\title{
绿色建筑设计理念在民用建筑设计中的应用
}

\author{
王 刚* \\ 青海建筑职业技术学院, 青海 810012
}

\begin{abstract}
摘 要: 绿色生态发展观念是我国当前时代的重点内容，绿色建筑设计理念能够有效践行我国的可持续发展战略。 本文通过对建筑设计过程中的绿色设计理念的应用情况展开分析, 并结合建筑设计的相关原则, 具体分析了绿色建筑设 计理念的应用方向, 以此来为建筑设计提供新的发展思路, 使得民用建筑在真正意义上成为绿色建筑。同时, 绿色设计 也能够推动绿色生产理念在我国生产活动中的应用，增强全民绿色发展意识，实现社会经济活动的可持续发展。
\end{abstract}

关键词: 绿色建筑设计; 民用建筑; 应用探究

\section{Application of Green Building Design Concept in Civil Building Design}

\author{
Gang Wang* \\ Qinghai Architectural College, Xining 810012, Qinghai, China
}

\begin{abstract}
The concept of green ecological development is the key content of China's current era. The concept of green building design can effectively practice China's sustainable development strategy. This paper analyzes the application of the concept of green design in the process of architectural design, and analyzes the application direction of the concept of green building design in combination with the relevant principles of architectural design, so as to provide new development ideas for architectural design and make civil buildings become green buildings in the real sense. At the same time, it can also promote the application of the concept of green production in China's production activities, enhance the people's awareness of green development, and realize the sustainable development of social and economic activities.
\end{abstract}

Keywords: Green building design; Civil building; Application exploration

一、引言

随着社会的快速进步, 人们对建筑的功能性提出了较高的要求, 那么在建筑设计及施工阶段, 就应当积极融入绿 色环保理念, 保证了民用建筑的使用符合当前时代的发展需求 ${ }^{[1]}$ 。在当今社会中, 绿色环保已经成为时代发展的主要 方向, 对于建筑设计而言, 就应当在保证建筑寿命周期的同时, 使用绿色建筑设计理念, 积极完善民用建筑的节能设 计, 从而保证在后续建设过程中, 能够践行我国可持续发展战略。通过建筑的绿色设计, 能够进一步实现节能减排的 生产目标，从而降低建筑工程给环境污染带来的影响，实现人与自然和谐发展。

\section{二、应用绿色建筑设计理念的重要性}

自从改革开放以来, 我国经济获得到了空前的发展, 人民的生活水平得到了有效提高, 而建筑行业作为推动我国 社会经济的重要产业, 就应当积极践行我国的发展策略 ${ }^{[2]}$ 。但是对于传统的建筑行业而言, 其资源消耗率较高, 而且 会造成十分严重污染情况, 这就会给生态环境带来巨大压力。而且建筑工程在建设过程中会产生大量的建筑垃圾 (如 图1所示）, 建筑垃圾的所占比例越高, 就越会对人们的生活环境造成严重影响。部分建筑设计理念不合理, 就会导 致在生产过程中过分使用高能耗建筑材料, 使得建筑造价较高、功能不全等情况比比皆是 ${ }^{[3]}$ 。

为了有效缓解这种情况, 就应当根据我国国情合理规划建筑设计, 在满足和人们居住需求的同时, 也应当控制资 源的消耗, 从而提高城市住宅的质量。绿色建筑设计里面就能够有效实现我国可持续发展目标, 在民用建筑建设过程

*通讯作者: 王刚, 1985年9月, 男, 汉族, 山西怀仁人, 任青海建筑职业技术学院讲师, 本科。研究方向: 建筑 设计方面的教育工作。 
中能够降低能源损耗污染排放。

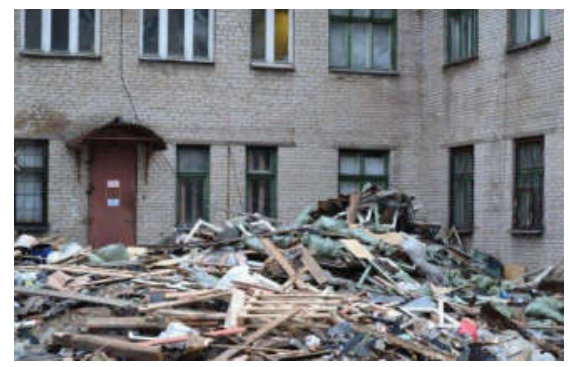

图1 某建筑项目建筑垃圾现场情况

当前世界人们都十分重视绿色生态发展理念, 各级政府也积极向社会宣传环保思想, 从而使得建筑工程的能够在真正 意义上实现减少污染、节能减排。为此我国颁布的大量有关于绿色生态发展的法律文件，从而推动绿色建筑设计的有效执 行, 在当前社会发展的影响下, 绿色建筑设计已经成为了民用建筑设计的重点内容, 在建筑施工过程中绿色建筑理念的利 用能够有效降低工程施工成本，提高建筑施工单位的经济效益，而且能够降低对周围环境的污染，减少能源消耗。

\section{三、绿色设计理念的基本原则}

在绿色建筑的设计工程进行中，包括工地附近的光照、风向、植被密度乃至土壤的质量都会影响其最终成品 ${ }^{[4]}$ 。 同时，绿色建筑设计也必须要践行以人为本的基本理念，因地制宜，在保证人们生活需求的同时尽可能地降低对自然 生态的影响，创建更加和谐的人与自然关系。

\section{(一) 系统规划设计原则}

随着建筑规模的不断扩大, 建筑设计工作也更加科学合理, 所以在绿色发展理念的推动下, 民用建筑在设计过程 中就应当运用绿色建筑设计理念完成整体规划。在设计民用建筑之前, 设计人员就应该根据建筑物的设计情况及其地 理条件进行合理规划，保证建筑物的整体结构更加合理。同时随着现代信息技术的快速发展，设计工作人员可以应用 3D建模技术来构建民用建筑模型（如图2所示）。根据模拟建筑的整体建设情况找出建筑设计中的不足，从而加以调 整。模型的周边也要做好设计规划，保证周边环境符合绿色生态理念，从而保证设计效果更加科学正确。由于民用建 筑的整体设计工作过于复杂, 施工单位要想保证工程施工的顺利进行, 尽量按照实际设计内容进行施工。总而言之, 房屋建筑就应当分别从设计及建筑融人绿色理念，通过科学合理的方式来提高建筑工程质量。

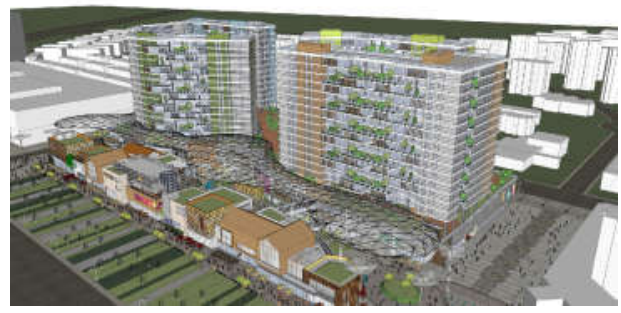

图2 建筑设计模型图

\section{（二）节约为主设计原则}

我国虽然能源储备量较大, 但是由于人口数量众多, 在生产过程中需要用到较多的能源, 进而导致能源稀缺的情 况, 因此在建筑设计过程中, 首先要对建筑工程进行合理的规划, 在使用原材料的过程中, 应当对资源合理分配, 进 行资源整合，避免在建筑过程中对材料在使用过程中造成不必要的浪费，进而提高能源的使用效率 ${ }^{[5]}$ 。

在工程的建筑过程中，我们要将绿色的发展理念落到实处，在建筑材料的选择上，我们应该在能力范围内尽量选 择环保价值高的建筑材料, 真正做到把绿色的建筑理念运用到施工项目中来。在设计过程中, 设计工作人员就应当 根据民用建筑结构特点及后期能源情况进行区域的资源分配，使得民用建筑类资源利用率最大化，从而有效降低能源 成本及经济建设成本。此外, 设计工作人员也应当科学考虑民用建筑的整体功能性, 并利用建筑物地区的优势将资源 使用量降到最低, 所以民用建筑的设计要将节约为主作为主要设计原则, 通过构建节约型民用建筑来降低整体能源消 耗，不断进行我国绿色发展理念。 


\section{(三) 和谐发展设计原则}

绿色建筑设计理念应当秉持人与自然和谐发展的设计原则。设计工作人员应当结合建筑的设计需求以及当地的地理条 件加强对房屋结构的设计。在设计房屋的外观时, 要避免使用过于明显的颜色, 根据周边的环境选择最为适合的颜色。同 时建筑风格也要与气候条件相同, 根据当地的实际风格完善设计内容。其次再对民用建筑内部进行设计, 是要合理使用自 然资源分床的位置要保证采光及取暖的需求, 而且室内的设计也要尽量凸显绿色生态的理念。因此民用建筑在设计过程中 要坚持人与自然共同发展的基本原则，而且建筑的设计也要满足人们居住的环境需求，实现环境保护的真正目的。

\section{四、绿色建筑设计理念的具体应用}

\section{(一) 保温技术}

建筑的散热会造成大量的能源损耗，而且在我国北方地区如果不完善，保温设计就难以提高房屋整体质量、为人 们提供温度足够的生活环境。所以在绿色建筑设计过程中, 就应当将经济建设作为设计的主要重点, 而最有效的方法 就是选择环保型保温材料。保温材料主要用于房屋建筑的外墙保温, 一般情况下，民用建筑会采用保温材料及结构强 化材料来稳定其保温层结构而常用的保温技术，包括薄抹灰外墙保温等等。通过保温技术的合理应用，既能够减少建 筑物散热、节约能源，还可以提高建筑物墙体的寿命及稳固程度，降低工程造价。

\section{(二) 阳台绿色设计}

在民用建筑设计过程中, 阳台是其设计的重要部分, 阳台作为人们重要的休闲场所具有重要的价值, 所以可以设 计阳台, 不仅能够为居民提供一个舒适的生活环境, 还能够实现节能减排。针对阳台的绿色设计, 首先就要综合考虑 阳台的质量问题, 比如可以设计成挑出式, 这样能够利用其自然条件。同时应当综合考虑阳台空间的地域问题, 例如 可以完善阳台的绿化景观设计, 让居民在家中就能感受到大自然的气息, 从而提高居住环境的美观度及整体适应度, 充分发挥其绿色作用，改善热环境，进而突出绿色环保理论。

\section{（三）门窗绿色设计}

由于我国南北方差异较大, 就导致不同地域的温度存在较大差异。因此门窗的保温功能设计具有重要作用, 尤其 是在我国北方地区房屋的保温功能至关重要。只有充分保障房屋的保温性能, 才能够为北方人民提供更加舒适的生活区 域。所以门窗的保温功能是衡量其好坏的重要指标。目前我国门窗的保温材料市场一般包括玻璃材料及铝合金等材料, 不同的选择具有不同的作用，在设计过程中进行当地建筑物的实验材料的选择最适合材料，从而达到保温的作用。

（四）室内外绿色环境设计

民用建筑物的房屋设计要充分考虑室内采光效果, 并根据建筑所处位置确定建筑的朝向, 一般情况下普通光照要 与局部光照相结合。而在选用室内灯具时也要尽量选择节能型, 减少电能的消耗。同时明建筑也要注意隔音问题, 再 选择墙体材料时, 要选择隔音效果较好的材料降低居民被噪声污染的可能性。而且墙体材料也要选择环保型材料。通 过大量环保型材料的选用, 不仅能够满足人们的物质需求, 又能提高全民对于绿色环保的建筑理念的认识。此外, 在 民用建筑的出口也应当合理设计风口，保证风向的合理性。

\section{五、结束语}

总而言之，随着现代社会的快速发展，人们对建筑物的功能性需求逐渐上涨，所以在满足人们技术需求的同时， 设计工作人员也应当将绿色设计理念融人到民用建筑设计之中, 进一步践行我国绿色发展理念。通过绿色建筑的施 工，能够进一步实现我国可持续发展理念的推动。

\section{参考文献:}

[1]戴建莉.浅谈民用建筑电气设计中绿色节能技术的应用[J].价值工程, 2021,40(14):229-230.

[2]钟坤.关于绿色节能技术在民用建筑电气设计中的应用路径试析[J].陶瓷, 2021(2):126-127.

[3]俞云耀.绿色设计理念在高层民用建筑设计中的应用途径分析[J].河南建材, 2021(3):124-125.

[4]韩平.高层民用建筑设计在绿色建筑设计中的应用 [J].建材与装饰, 2020(1):89-90.

[5]昌晓虎.浅谈高层民用住宅设计中绿色建筑设计理念的应用[J].中国建筑装饰装修, 2020(7):83. 